\title{
Designing a Model for Swimming Coaches' Job Retention based on Talent Management and Quality of Working Life
}

\author{
${ }^{1}$ Pouya Afkhami, ${ }^{1}$ Hossein Sepasi", ${ }^{1}$ Parivash Nourbakhsh \\ ${ }^{1}$ Department of Sports Management, Faculty of Sports Science, Karaj Branch, Islamic Azad University, \\ Karaj, Iran.
}

Submitted 06 September 2019; Accepted in final form 01 November 2019.

\begin{abstract}
Background. Organizations are always trying to retain and empower their talented employees so that they can perform well. However, they are still afraid of losing their human capital. Objectives. The purpose of this study was to design a job retention model for swimming coaches based on talent management and the quality of working life. Methods. It was an applied descriptive-survey study. The statistical population included the swimming coaches of East Azarbaijan province (773 persons). According to the Cochran formula, 285 people were selected by a stratifiedproportional random sampling method. Data collection tools included Katajar Employees' Talent Management Questionnaire (2012), Stephen et al.'s (2015) Quality of Working Life Questionnaire and a Researcher-made Job Retention Questionnaire. Results. The results showed the direct and significant effect of talent management and quality of working life on job retention. The mediator role of quality of working life also had a mediating effect on the relationship between talent management and job retention. Finally, the proposed model has a good fit. Conclusion. Since talent management system plays an essential role in enhancing the quality of working life and job retention of swimming coaches, managers and officials of swimming federation need to do careful planning to improve the talent management system.
\end{abstract}

KEYWORDS: Job Retention, Talent Management, Quality of Working Life, Coaching, Swimming

\section{INTRODUCTION}

Given the critical role of coaches in sports, recruiting and subsequently maintaining good quality coaches in sports programs is very important. Every year a significant number of coaches leave coaching. This change can have devastating effects on athletes, sports programs and coaches. For example, it can be a source of stress for athletes and a limiting factor in establishing a strong relationship between coach and athlete (1). Approximately $35 \%$ of coaches cease to work with the US Swimming Federation each year. Sports organizations recognize that coaching is essential for maintaining quality sports programs, and therefore consider coaching turnover as an important issue. However, the reasons why some people continue to coach and some leave coaching are not well understood (2). Studies show that over the next five years, global staff turnover rates will increase from $20.6 \%$ to $23.4 \%$ (3).

The turnover rate of coaches is not only costly but also has broader implications for sports programs and sports. Coaches are crucial to the development of sports culture, and sports organizations know that coaching is essential for maintaining sport quality (4).

The task of coaching has been described as very valuable and, at the same time, very

*. Corresponding Author:

Hossein Sepasi, Professor

E-mail: hosseinsepasi@yahoo.com 
stressful. Records show that coaches who feel supportive of their organization are less likely to think about coaching turnovers, so sports organizations should start sharing conversations with coaches about the organizational stressors (5). Knowing the factors that influence coaches' decisions to continue or leave coaching may allow organizations to take steps to retain coaches (6). The particular value created by talented employees and their stake in organizations in a highly competitive global economy has made talent management a strategic priority for organizations. Talent management is advocated as an essential strategy for retaining talented employees, but the academic studies that examine their relationships are limited. The ability to develop and implement integrated talent management is seen as a roadmap for organizational success, with benefits such as increased employee returns, less downsizing, lower turnover among top employees, lower voluntary turnover rates, and more exceptional ability to hire the best talent and to develop great leaders (3). The success of organizations depends to some extent on the challenges faced in identifying, recruiting, managing and retaining talent as well as adapting to these challenges as they evolve that requires managing talented staff (7). For organizations to benefit fully from the implementation of talent management, managers need to be aware of the organization's talents and to communicate with them continuously through talent management practices (8).

Another critical factor that can affect employees' job retention is the quality of working life. Probably the term quality of work-life originated from the first International Labor Relations Conference at Arden House, Columbia University in New York in 1972 (9). The focus of quality of working life is on improving employee well-being and organizational performance, defined as employees' perceptions of how working conditions in an organization can meet their personal and work needs (10). Quality of working life includes feelings about job content, physical work environment, salaries, benefits, promotions, autonomy, teamwork, decision making, occupational health and safety, job security, communication, peer and manager support, and work-life balance (11). The focus on the quality of working life today is a reflection of the importance that everyone attaches to it. Many employees are dissatisfied with their job, looking for more meaningful work. Research findings showed that implementing these programs reduces staff complaints, reduces absenteeism, stress, and conflict between management and practice, reduces discipline, enhances employees' positive attitudes, and increases their participation in job offerings programs, job security, and their functioning (12). Many swimming coaches drop out of coaching after a short period, looking for another job or looking for a second job. The low retention rate of swimming coaches seems to be related to some components of the quality of working life and talent management.

Therefore, due to the importance of the subject and the role of coaches in the training of athletes and the lack of research on talent management, quality of working life and job retention among swimming coaches, the researcher seeks to answer the question of what is the relationship between talent management and job retention of swimming coaches with the mediating role of the quality of working life?

In a study evaluating coaches' job retention strategies at sports clubs in South Africa, Surujlal and Grobler (2014) outlined several plans for staying in the coaching profession: rewards, training and development, participatory decision making, resource allocation, and budgeting and participation in classification and contracts (13).

Monsah's (2019) results showed that talent management had a direct and indirect impact through perceived organizational support on turnover intention (8). Also, Osaru (2019), Qusi, Mehravar, and Shakeri Navai (2016), Saberfard and Deira (2014) and Hosseini (2011) showed that there was a significant positive relationship between talent management and job retention (1417).

Ogbuabor and Okoronkwo (2019), Parveen, Maimani and Kassim (2017), Korunka, Hoonakker and Carayon (2008), Chan and Wyatt (2007), Siegrist, Wahrendorf, Von dem Knesebeck, Jürges and Börsch-supan (2007), among others showed that the quality of working life affects the turnover rate of employees (1822). The results of this study can identify areas for improvement in enhancing swimming coaches' positive job retention factors, and senior executives can design effective strategies and targeted programs for better coaching performance, and thus witness the remarkable progress of swimmers and coaches so that we'll 
get better results at international competitions, including the Olympics.

The purpose of the present study was to present a model of job retention of swimming coaches based on talent management and the quality of working life. Although researchers in their conceptual models have referred to different factors for measuring job retention, talent management, and quality of working experience, they did not use structural equation modeling for job retention, talent management and quality of working life among swimming coaches. Also, a nativized instrument has not been used for studying these variables. Based on the above, which is based on theories and background in this field, the conceptual model of the research is presented in Figure 1.

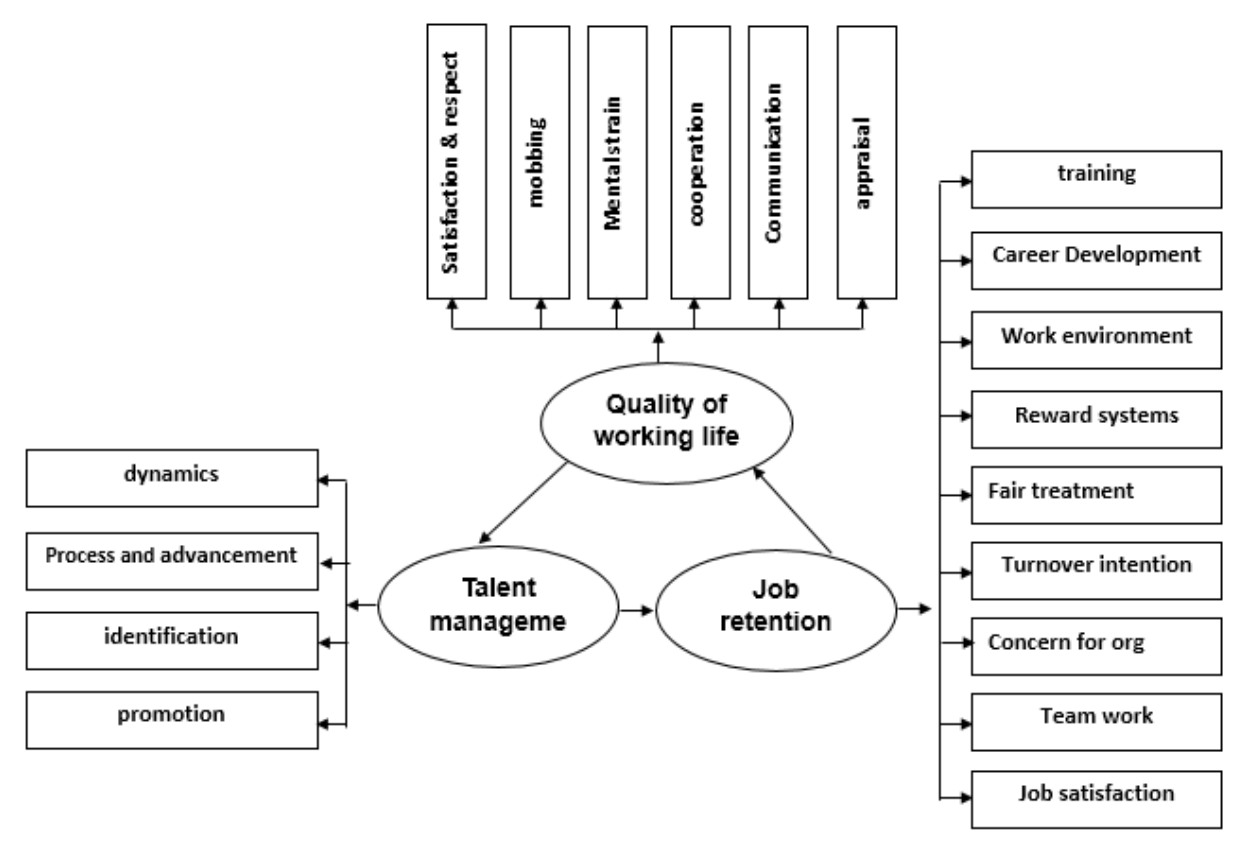

Figure 1. Conceptual Model of Swimming Coaches' Job Retention based on Talent Management and Quality of Working Life

\section{MATERIALS AND METHODS}

Research Design. The purpose of this study was applied a descriptive-survey correlation using structural equation modeling.

Participants. The statistical population of the present study was all swimming coaches of East Azerbaijan province. According to the information obtained from East Azarbaijan Swimming Pool, the total number of coaches (Grade 3, Grade 2, Grade 1, International and Lecturer) was 773 and there were 420 women and 353 men coaches. In the present study, the Cochran formula was used to select the sample size for greater confidence in obtaining the optimum sample size due to the probability of a lack of access to the total population. Using Cochran's formula, 256 was obtained and 285 individuals were selected by stratified-random sampling considering the likelihood of noncooperation.
Instruments. In this study, three questionnaires were used for data collection, two of which are standard questionnaires, and one is a questionnaire designed by the researcher. The Katajar (2012) talent management questionnaire consisting of 15 closed-ended questions that measure four components of dynamics, process and advancement, identification and promotion were used based on the five-point Likert scale (23). Its reliability was measured and confirmed by Cronbach's alpha $(\alpha=0.78)$. The Stephen et al. (2015) quality of working life questionnaire containing 21 questions and six dimensions of satisfaction and respect, mobbing, mental strain at work, collaboration, communication and feedback, and appraisal was used. In the study of Stephen et al. (2015), to examine construct validity, regression analysis was performed which had satisfactory results (24)., The internal reliability of the questionnaire, was calculated 
through Cronbach's alpha $(\alpha=0.84)$. To construct the job retention questionnaire, Leon, Shi, Yen, Jin, and Qing (2013), Kumar (2013) and Hoseini Shahpur (2012) studies were used (25). The first 13 factors consisted of 105 questions. In a qualitative study conducted by professors and experts, duplicate questions and elements that were not commensurate with the work environment of swimming coaches were eliminated and corrections were made. A pilot questionnaire was administered to examine the psychometric properties among a sample of 150 instructors. Finally, after analyzing the correlation coefficients, exploratory factor analysis and confirmatory factor analysis of job retention questionnaire with eight factors, 44 questions were investigated, and Cronbach's alpha coefficient of 0.94 was obtained.

Data collection. For better sampling, the province was divided into three regions: north, center, and south. To determine the sample size of each district according to Table 1, based on the definition of the cluster sampling method, the ratio of the number of coaches in each district to the total number of coaches in the province was calculated. Given the difficulties and disadvantages faced by the researcher in the initial stage when they were visiting and requesting a questionnaire in the pool environment, they preferred to send the surveys electronically. Finally, 285 questionnaires were completed with follow-up.

Table 1. Sample Size by Region

\begin{tabular}{|lccccc|}
\hline Zone & Male coach & Female coach & Total & Sample share & Sample size \\
(Center 1) & 226 & 339 & 565 & $73 \%$ & $73 \% * 300=219$ \\
(North 2) & 21 & 15 & 36 & $5 \%$ & $5 \% * 300=15$ \\
(South 2) & 106 & 66 & 172 & $22 \%$ & $22 \% * 300=66$ \\
Total & 353 & 420 & 773 & $100 \%$ & $\mathrm{~N}=300$ \\
\hline
\end{tabular}

Statistical Analysis. The structural equation modeling method was used to investigate the hypotheses and to evaluate the fit of the job retention model based on talent management and quality of working life. However, before testing the theories, it was necessary to examine the normality assumption. For this purpose, the Kolmogorov-Smirnov test was used. Considering the significant levels (significance levels greater than 0.05), it is concluded that the variables of talent management, job retention and quality of work-life had a normal distribution and therefore, parametric tests were used.

\section{RESULTS}

According to Table 2 of the total sample, $32.6 \%$ were female, and $67.4 \%$ were male. In terms of marital status, $42.1 \%$ were single and $57.9 \%$ were married. In terms of education level, the highest frequency was a bachelor degree with $40.7 \%$. In terms of coaching, grade three was the most abundant with 54 percent. Most coaches (72.6\%) were from the provincial capital.

In terms of age and coaching experience, the mean age of the coaches was 32.62 years, the youngest was 18 , and the oldest was 57 years. The average coaching experience was 10.06 years, the lowest was one and the highest was 40 years.

For the research variables, mean, standard deviation, skewness, elongation, minimum and maximum were calculated. Scores can range from one to five. The results are presented in Table 3.
The skewness and elongation coefficients of the variables were less than one, indicating that none of the variables were outliers, and the data distribution was normal.

\begin{tabular}{|c|c|c|}
\hline Sub-index & Frequency & Percent \\
\hline \multicolumn{3}{|l|}{ Sex } \\
\hline Female & 93 & 32.6 \\
\hline Male & 192 & 67.4 \\
\hline Total & 285 & 100.0 \\
\hline \multicolumn{3}{|l|}{ Marriage status } \\
\hline Single & 120 & 42.1 \\
\hline Married & 165 & 57.9 \\
\hline Total & 285 & 100.0 \\
\hline \multicolumn{3}{|l|}{ Education level } \\
\hline Diploma & 10 & 3.5 \\
\hline Associate & 33 & 11.6 \\
\hline Bachelor of science & 116 & 40.7 \\
\hline Master of science & 112 & 39.3 \\
\hline Ph. D. & 14 & 4.9 \\
\hline Total & 285 & 100.0 \\
\hline \multicolumn{3}{|l|}{ Field of study } \\
\hline Non-physical education & 133 & 46.7 \\
\hline Physical education & 152 & 53.3 \\
\hline Total & 285 & 100.0 \\
\hline \multicolumn{3}{|l|}{ Coaching degree } \\
\hline Grade 3 & 154 & 54.0 \\
\hline Grade 2 & 83 & 29.1 \\
\hline Grade 1 & 27 & 9.5 \\
\hline International & 9 & 3.2 \\
\hline Lecturer & 7 & 2.5 \\
\hline Total & 285 & 100.0 \\
\hline \multicolumn{3}{|l|}{ Zone } \\
\hline Center & 207 & 72.6 \\
\hline North & 15 & 5.3 \\
\hline South & 63 & 22.1 \\
\hline Total & 285 & 100.0 \\
\hline
\end{tabular}

The bootstrapping method was used to investigate the mediating effect of quality of 
working life on the relationship between talent management and job retention. In this method, the main results of the independent and dependent variables were first examined. If the two variables were significant, the mediator variable entered into the model and the three variables were examined. If both direct and indirect effects were significant, there was a partial mediating effect, and if immediate effect was insignificant and the indirect effects were significant, there is a full mediating effect. According to Table 4, it was observed that without the intervention of the quality of working life, talent management had a significant positive relationship with job retention $(\mathrm{p}=0.001, \mathrm{t}=5.07)$. Therefore, mediation analysis can be continued. The standardized regression coefficient for an indirect path of talent management - the quality of work-life -on job retention was 0.41 at a $95 \%$ confidence level significant.

On the other hand, in the mediator model, the direct path of talent management with job retention was significant at a $95 \%$ confidence level $(p=0.001)$. It is therefore concluded that the quality of working life had a mediating effect on the relationship between talent management and job retention. The values in Table 4 showed that the conceptual model of the research was wellfitted.
Fit indices have three types of absolute, adaptive, and purposive that must be reported for each of the classes. In this study, at least two cases were reported. If at least three indices are acceptable, it can be concluded that the model is well-fitted. The significance level of the chisquare statistic was 0.001 which is not acceptable according to the criterion considered (higher than 0.05). However, since the level of significance is sensitive to the number of samples and is almost always significant in large samples, other indices have been used to evaluate the fit of the model. The values in Table 5 show that the conceptual model of the research was well-fitted. According to the structural model presented in Figure 2, it is observed that talent management had a significant positive relationship with job retention. The impact intensity was 0.27 .

In other words, with one standard deviation increase in talent management, job retention increases by 0.27 standard deviations. Besides, the quality of working life had a significant positive relationship with job retention and the magnitude of the impact was 0.64. Finally, talent management had a meaningful positive correlation with the quality of working life and the importance of impact was 0.47 .

Table 3. Descriptive Indexes of Talent Management, Job retention and Quality of Working Life

\begin{tabular}{|lccccccc|}
\hline Variables & $\mathbf{N}$ & mean & Kurtosis & Skewness & Std. Deviation & Minimum & Maximum \\
Talent management & 285 & 3.80 & -0.10 & -0.05 & 0.37 & 2.67 & 4.80 \\
Job retention & 285 & 2.93 & 0.05 & -0.03 & 0.64 & 1.32 & 4.93 \\
Quality of working life & 285 & 3.14 & 0.20 & 0.13 & 0.39 & 1.95 & 4.29 \\
\hline
\end{tabular}

Table 4. Coefficients based on the Structural Model of the Impact of Talent Management on Job Retention by Mediating Quality of Work Life

\begin{tabular}{|c|c|c|c|c|c|c|}
\hline Path & $\mathbf{R}^{2}$ & SE & C.R & $\begin{array}{c}\text { P- } \\
\text { value }\end{array}$ & $\begin{array}{l}\text { Standard Direct } \\
\text { Effect }\end{array}$ & $\begin{array}{l}\text { Standard total } \\
\text { Effect }\end{array}$ \\
\hline $\begin{array}{l}\text { The Direct Effect of Talent Management on Job retention } \\
\text { (Without Mediating Quality of Working Life) }\end{array}$ & 0.869 & 0.171 & 5.070 & 0.001 & 0.564 & 0.564 \\
\hline $\begin{array}{l}\text { The Direct Effect of Talent Management on Job retention } \\
\text { (With Mediating Quality of Working Life) }\end{array}$ & 0.425 & 0.122 & 3.494 & 0.001 & 0.271 & 0.571 \\
\hline The indirect Effect of Talent Management on Job retention & 0.632 & 0.072 & - & 0.001 & 0.409 & - \\
\hline
\end{tabular}

Table 5. Fit Indexes of Structural Model of the Impact of Talent Management on Job Retention by Mediating Quality of Working Life

\begin{tabular}{|l|ccc|}
\hline Fit index & Criteria & Value & Conclusion \\
Absolute & & & \\
$\quad$ CMIN/DF & $\leq 5$ & 4.41 & Ideal \\
p-value x2 & $\geq 0.05$ & 0.001 & bad \\
GFI & $\geq 0.90$ & 0.95 & Ideal \\
Comparative & & & \\
TLI & $\geq 0.90$ & 0.89 & Ideal \\
CFI & $\geq 0.90$ & 0.92 & Ideal \\
Parsimony & & & \\
$\quad$ RMSEA & $\leq 0.08$ & 0.069 & Ideal \\
PNFI & $\geq 0.5$ & 0.66 & Ideal \\
\hline
\end{tabular}




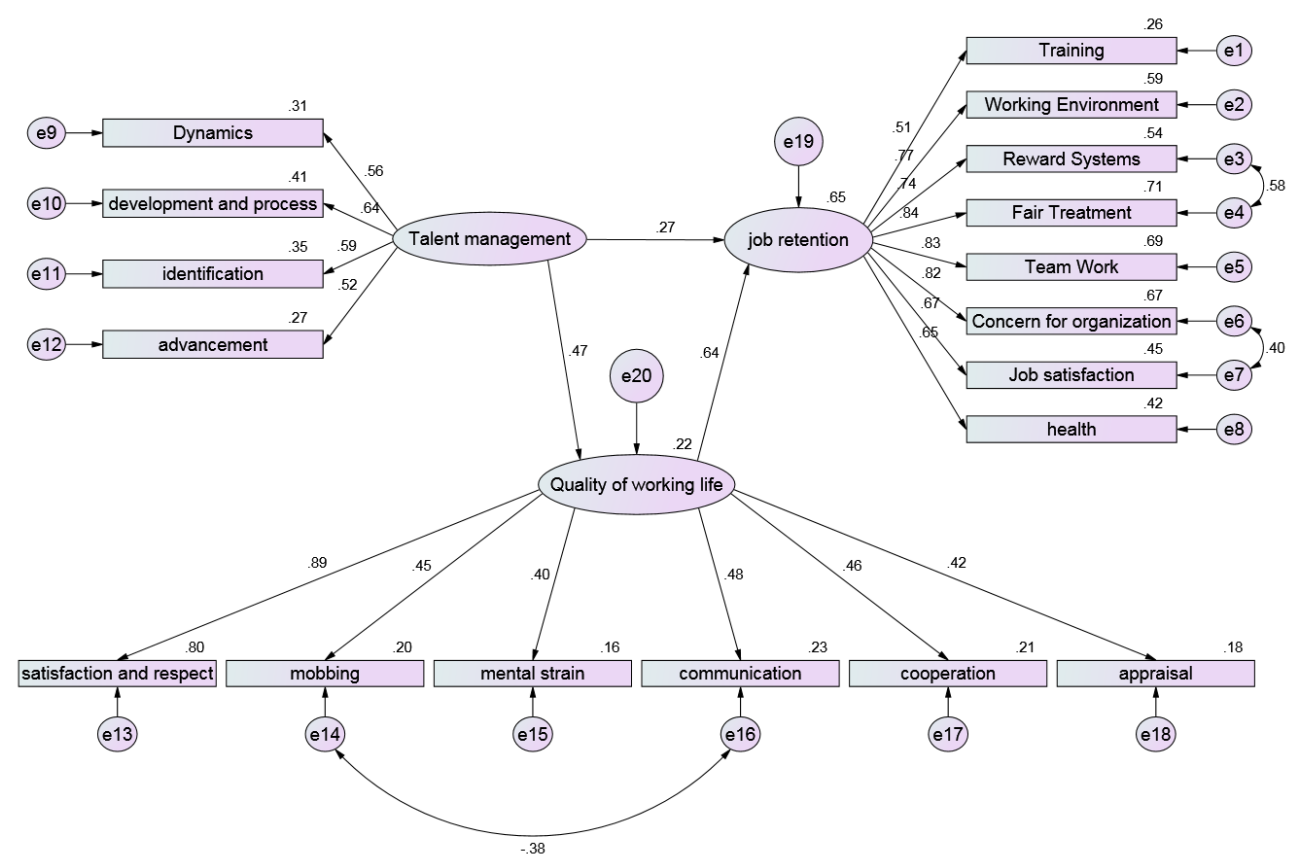

Figure 2. Research Structural Model; Amos Software Output

Pearson correlation test was used to examine the relationship between age and coaching experience with job retention, talent management, and quality of working life of coaches. Pearson correlation results in Table 6 showed that there was no significant relationship between coaches' age with job retention, talent management and quality of working life $(\mathrm{p}<0.05)$. Also, there was no significant relationship between coaching experience with job retention and talent management $(p<0.05)$. However, there was a significant positive relationship between coaching experience and quality of work-life $(\mathrm{r}=$ $0.16, \mathrm{p}<0.05)$.

Table 6. Pearson Correlation Test to Investigate the Relationship between Age and Coaching Experience with Job Retention, Talent Management and Quality of Work Life

\begin{tabular}{|l|ccc|}
\hline & $\begin{array}{c}\text { Talent } \\
\text { management }\end{array}$ & $\begin{array}{c}\text { Job } \\
\text { retention }\end{array}$ & $\begin{array}{c}\text { Quality of } \\
\text { working life }\end{array}$ \\
$\begin{array}{l}\text { Correlation } \\
\text { coefficient }\end{array}$ & -0.003 & -0.058 & 0.052 \\
$\begin{array}{c}\text { p-value } \\
\text { Coaching } \\
\text { experience (years) }\end{array}$ & 0.962 & 0.327 & 0.380 \\
$\begin{array}{c}\text { Correlation } \\
\text { coefficient }\end{array}$ & 0.018 & 0.010 & $0.164^{* *}$ \\
p-value & 0.756 & 0.868 & 0.005 \\
\hline
\end{tabular}

\section{DISCUSSION}

The results of the structural model analysis showed that talent management had a significant positive causal relationship with job retention of swimming coaches in East Azarbaijan province. Therefore, the talent management of swimming coaches leads to a more extended stay in their job. Talent management is a series of integrated activities designed to ensure that talent is attracted, motivated, and retained, at present and in the future by the organization. The goal of talent management is to develop and maintain a pool of talents consisting of the skilled, engaged and committed workforce to ensure the flow of talent.

Talent management ensures that the right people with the right skills are in the right place and focused on, and engaged in, the right activities. Awareness of the leaders of organizations that it is their employees' talents and abilities that drive their business to success can help organizations engaging in talent management and striving to retain employees with their potential. Mansah (2019), Osaru (2019), Narayanan (2018), Ghusi and others (2016), Saberfard and Deira (2014), and Hosseini (2011) also concluded that talent management enhances job retention $(3,8,15$ 17).

The results of the structural model analysis showed that there is a significant positive relationship between the quality of working life with job retention of swimming coaches in East Azarbaijan province. Quality of work-life enhances employee loyalty to the organization and reduces turnover rates, absenteeism, and strife between managers and employees. Coaches should be considered as the growing human 
resources of the organization and their learning, growth and professional development will be a factor in continuing to provide quality services in the organization.

Studies by Ogbuabor and Okoronkwo(2019) and Al-Maleki et al. (2012) showed that organizations with high levels of quality of working life showed high productivity, low turnover rate and high job satisfaction $(10,18)$. Also Parvin et al. (2017), Korunka, Hoonakker and Carayon (2008) and Chan and Wyatt (2007) cited improved quality of life as a reinforcing factor for job retention $(19,21,22)$.The results of the structural model analysis showed that talent management had a significant positive causal relationship with quality of working life in the coaches of East Azarbaijan province. Applying talent management and its four components (dynamics, process and growth, cognition and promotion) had a positive effect on improving the quality of working life of coaches. Improving the quality of working life leads to coaches' motivation for better work, increased job satisfaction and better collaboration resulting in a better attitude towards the organization and all of these factors lead people to perform better in the organization. Ultimately, it increases the productivity of the organization. Fibrinanda et al (2018) also found that having a talent management system helps organizations increase the quality of working life of employees (26).

Finally, the results of the structural model analysis showed that the indirect effect of talent management on job retention of coaches through the quality of working life was significant and means that talent management can lead to increased job retention by improving the quality of working experience of coaches. Mansah (2019) demonstrated the direct and indirect impact of talent management on job retention through perceived organizational support mediation (8). It is suggested that corporate managers adhere to the principles of talent management to facilitate coaches' job retention commitment, which in addition to enhancing job retention, can positively lead to the quality of working life of coaches. Moreover, with the increase in talent management in the organization, coaches will shift to more collaboration, communication and feedback, while reducing organizational bullying and work pressure, thereby enhancing the organization's growth and job retention. The results showed that there was no significant relationship between age and coaching experience with job retention, talent management and quality of working life coaches except one case that there was a meaningful positive relationship between coaching experience and quality of working life coaches that means with increasing work experience, swimming coaches have a higher quality of working life. Coaches with a managerial background are likely to be more respected and considered in decisions, and less likely to be mentally challenged than those with no prior experience.

\section{CONCLUSION}

Given the critical role of coaches in swimming, it is essential to retain and subsequently maintain good quality coaches in sports. Coaches are skilled people who work with athletes of all ages in different fields. Educators have a tremendous impact on children and adolescents and often commit them to produce internationally competitive results that are the basis of a country's pride and identity. However, retaining coaches has become a severe challenge for sports organizations in recent years. Swimming is one of the most popular Olympic sports, with many medals being distributed and ranked second in the Olympics with 34 medals. This explains the importance of swimming, especially in the Olympics. More attention should be paid to this sport in Iran. In this regard, the present study aimed at providing a model of effective factors in job retention of swimming coaches and it was found that this model for suitable for developing job retention swimming coaches.

Like any other study, the present study had limitations. As the primary research questionnaire was set up electronically and online, the lack of internet literacy of some educators to complete the survey was considered a limitation. The psychometric properties of the research questions were evaluated on a small sample of swimming coaches. It is best to test these features on a larger sample. Finally, this research is limited to the swimming coaches of East Azerbaijan province.

Looking at the research background, it is clear that there was no research into the factors affecting job retention of swimming coaches in the leading countries. It is, therefore, necessary to examine the factors affecting the development of job retention of swimming coaches in leading 
countries such as the United States, Australia, Germany and China in future studies.

\section{APPLICABLE REMARKS}

- According to the results, talent management has a direct and indirect effect on job retention of swimming coaches. Therefore, it is recommended that managers and officials of the Swimming Federation increase job retention by providing appropriate areas of dynamics, growth, recognition and promotion among coaches.

- The results showed that quality of working life has a positive effect on job retention of swimming coaches. Therefore, managers can enhance the quality of working experience and subsequently the job retention of coaches by closing appropriate contracts, involving coaches in decision making and communication, giving feedback on coach performance and respectful behavior.

- According to the results, seventy-three percent of swimming coaches are in the capital of the province. However, the north and south of the area have a small share of swimming coaches. Therefore, to decentralize, it is suggested that more coaching classes be held in the north and south of the province to develop swimming coaches' abilities.

- According to the results, most swimming coaches have a degree in coaching. Therefore, it is suggested that second, first, international, and school coaching classes be held in the province.

\section{REFERENCES}

1. Knight CJ, Rodgers WM, Reade IL, Mrak JM, Hall CR. Coach transitions: Influence of interpersonal and work environment factors. Sport Exercise Perform Psychol 2015;4(3):170-187. doi: 10.1037/spy0000036

2. Raedeke TD, Warren AH, Granzyk TL. Coaching commitment and turnover: a comparison of current and former coaches. Res Q Exerc Sport. 2002;73(1):73-86. doi: 10.1080/02701367.2002.10608994 pmid: 11926487

3. Narayanan A, Rajithakumar S, Menon M. Talent Management and Employee Retention: An Integrative Research Framework. Hum Resour Dev Rev. 2019:1534484318812159.

4. Shipherd AM, Wakefield JC, Stokowski S, Filho E. The influence of coach turnover on student-athletes' affective states and team dynamics: An exploratory study in collegiate sports. Int J Sports Sci Coach 2018;14(1):97-106. doi: 10.1177/1747954118766465

5. Kilo RA, Hassmén P. Burnout and turnover intentions in Australian coaches as related to organisational support and perceived control. Int $J$ Sports Sci Coach 2016;11(2):151-161. doi: $10.1177 / 1747954116636710$

6. Cooper-Hakim A, Viswesvaran C. The construct of work commitment: testing an integrative framework. Psychol Bull. 2005;131(2):241-259. doi: 10.1037/0033-2909.131.2.241 pmid: 15740421

7. Gallardo-Gallardo E, Nijs S, Dries N, Gallo P. Towards an understanding of talent management as a phenomenon-driven field using bibliometric and content analysis. Hum Resour Manage Rev 2015;25(3):264-279. doi: 10.1016/j.hrmr.2015.04.003

8. Mensah JK. Talent management and talented employees' attitudes: mediating role of perceived organisational support. Int Rev Adm Sci. 2019;85(3):527-543. doi: 10.1177/0020852319844318

9. Sinha C. Factors affecting quality of work life: Empirical evidence from Indian organizations. Austr $J$ Busin Manage Res 2012;1(11):31-40.

10. Almalki MJ, Fitzgerald G, Clark M. Quality of work life among primary health care nurses in the Jazan region, Saudi Arabia: a cross-sectional study. Hum Resour Health. 2012;10:30. doi: 10.1186/1478-449110-30 pmid: 22971150

11. Raj Adhikari D, Gautam DK. Labor legislations for improving quality of work life in Nepal. Int J Law Manage. 2010;52(1):40-53. doi: 10.1108/17542431011018534

12. Saklani D. Quality of work life in the Indian context: An empirical investigation. Decision (0304-0941). 2004;31(2).

13. Surujlal J, Grobler WCJ. Retaining Sport Coaches: A qualitative Assessment of Retention Strategies at Sport Clubs in South Africa. Mediterr J Soc Sci 2014. doi: 10.5901/mjss.2014.v5n2p651

14. Osaro C. Talent Attraction and Employee Retention in Oil Firms in Rivers State. Int J Novel Res Hum Soc Sci. 2016;3(2):75-84. 
15. Ghosi S, Mehrara A, Shakeri Navahi G. Talent management role in the preservation of human resources potential in the Oil Products Distribution Company Sari area. Q J Farayand. 2016;10(52):251-275.

16. Saberfard O, Deyreh E. The effects of talent management and job retention on entrepreneurial attitude of employees at Bushehr education office. International Conference on Management; Tehran, Iran: Institute of Safirane Mobin; 2014.

17. Hoseini A. The Role of Talent Management in Providing and Preserving Talented Human Resources. $Q$ J New Econom Trade. 2011;6(24):181-205.

18. Ogbuabor DC, Okoronkwo IL. The influence of quality of work life on motivation and retention of local government tuberculosis control programme supervisors in South-eastern Nigeria. PLoS One. 2019;14(7):e0220292. doi: 10.1371/journal.pone.0220292 pmid: 31339944

19.Parveen M, Maimani K, Kassim NM. Quality of work life: The determinants of job satisfaction and job retention among RNs and OHPs. Int J Qual Res. 2017;11(1):173-194.

20.Korunka C, Hoonakker P, Carayon P. Quality of working life and turnover intention in information technology work. Hum Factors Ergon Manufact. 2008;18(4):409-423. doi: 10.1002/hfm.20099

21. Chan KW, Wyatt TA. Quality of Work Life: A Study of Employees in Shanghai, China. Asia Pacific Busin Rev 2007;13(4):501-517. doi: 10.1080/13602380701250681

22.Siegrist J, Wahrendorf M, von dem Knesebeck O, Jurges H, Borsch-Supan A. Quality of work, wellbeing, and intended early retirement of older employees: baseline results from the SHARE Study. Eur J Public Health. 2007;17(1):62-68. doi: 10.1093/eurpub/ck1084 pmid: 16777840

23. Cutajar B. The Impact of Organisational Culture on the Management of Employees' Talents: The Case of Maltese ICT Organisations. Leicester: University of Leicester; 2013.

24. Steffgen G, Kohl D, Reese G, Happ C, Sischka P. Quality of Work: Validation of a New Instrument in Three Languages. Int $J$ Environ Res Public Health. 2015;12(12):14988-15006. doi: 10.3390/ijerph121214958 pmid: 26703634

25. Chua B, Ng P, Tan C, Teoh Y, Wong S. Study of the relationship between retention strategies and job performance in Malaysia banking industry. Malaysia: Universiti Tunku Abdul Rahman; 2013.

26. Febrinanda C, Secapramana L, Nugroho J. Making talent management system to support quality of work life. The 6th Congress of asean regional union of psycholological society; Bali, Indonesia2018. 